\title{
LOWERING OF THE GROUND WATER TABLE - DOES IT AFFECT THE FRESH/SALT WATER INTERFACE, AND CAN WE MEASURE IT?
}

\author{
Thomas Vangkilde-Pedersen, Henrik Olsen and Peter $M$. Duch, \\ RAMBØLL, Bredevej 2, DK-2830 Virum, Denmark
}

\section{INTRODUCTION}

The Danish supply of potable water is mainly based on ground water. During construction work in areas with a shallow ground water table, temporary lowering of the water table is often necessary. In coastal regions, if the lowering of the water table is close to existing water abstraction sites, the ground water quality can be threatened by changes in the depth to the freshwater/saltwater interface.

With an example from Vestamager near Copenhagen, Denmark a combination of geophysical methods for monitoring the freshwater/saltwater interface is demonstrated. The example illustrates the advantages of combining geophysical well logging in observation wells with time domain electromagnetic (TDEM) soundings.

\section{A LOCAL GROUND WATER LOWERING}

During the construction works for the Fixed Link across Øresund, between Denmark and Sweden, extensive ground water lowering was performed in connection to the land works south of Copenhagen, Denmark. The ground water table was generally lowered approximately $3 \mathrm{~m}$ along the Øresund alignment for the railway and highway construction works. However, locally up to $c$. $15 \mathrm{~m}$ lowering of the ground water table was maintained for shorter periods.

A local ground water lowering to level -6 to $-8 \mathrm{~m}$ was maintained for a period of 4 months in Vestamager. The primary acquifer in this area is a Danian (lower Tertiary) limestone, which is met at a level of approximately $8 \mathrm{~m}$. The pre-land-work ground water table was situated at level c. $0 \mathrm{~m}$. For a period of more than two years the ground water table had been lowered to level -3 to $-5 \mathrm{~m}$ at this locality. The consequences of the additional lowering for the potable water supply wells nearby was feared in terms of a rise of the freshwater/saltwater interface.

It was decided to monitor the freshwater/saltwater interface by means of geophysical surveys. RAMBOLL suggested a combination of borehole logging and TDEM soundings and carried out two geophysical surveys, one at the upstart of the ground water lowering and one at the end of the lowering. The geophysical surveys were supplemented by chemical analysis of ground water samples taken at 2 months intervals.

\section{THE GEOPHYSICAL SURVEY}

Traditional fluid conductivity logs in observation wells are often inaccurate - in the worst case misleading, as the water in the well at a given level differs from the formation water. Experiences from the land works for the Fixed Link showed that the definition of the freshwater/saltwater interface by use of fluid conductivity logs commonly was misleading. Accordingly, it was decided 
to use a combination of neutron-porosity and electromagnetic logs to calculate the conductivity of the formation water, i.e. the ground water in place. The Archie formation factor relationship (Schlumberger, 1989) was used to calculate the formation water conductivity. Due to the small well diameters the influence of the water in the wells on the induction conductivity readings was considered negligible.

Fluid conductivity logs and calculated formation-water-conductivity logs were compared with salinity measurements on water samples. The freshwater/saltwater interface was clearly defined by the calculated logs and confirmed by water samples, whereas the fluid conductivity logs commonly indicated an apparent interface at an incorrect position (Fig. 1).

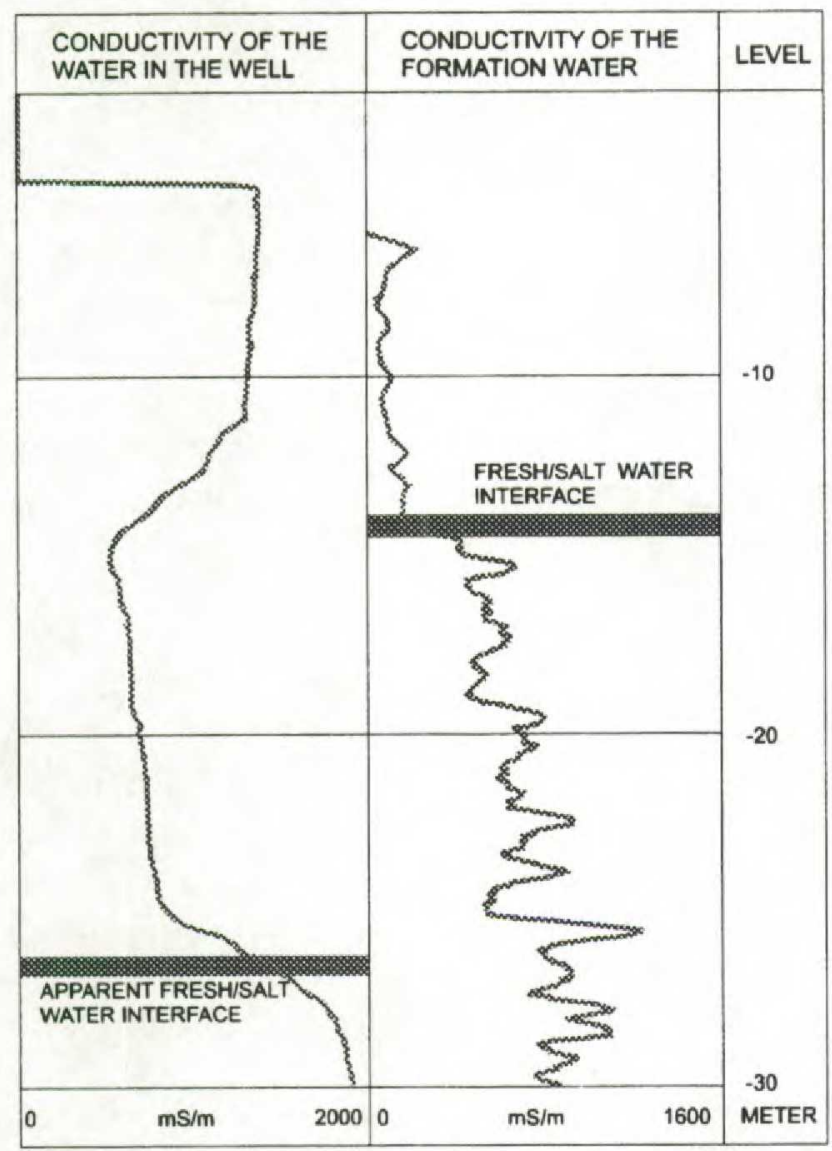

Fig. 1. Comparison of the conductivity of water in the well and of the formation water. The formation water conductivity is calculated from the electromagnetic $\log$ and the neutron-porosity $\log$. The conductivity of the water in the well results in an erroneous interpretation of the freshwater/saltwater interface, whereas the calculated log results in the correct interpretation.

Generally the calculated conductivity of the formation water was less than $200 \mathrm{mS} / \mathrm{m}$ above the interface and 400-1000 mS/m below the interface, commonly increasing with depth. Accordingly, the interface, which is here termed the freshwater/saltwater interface represents an interface between freshwater with a relatively constant salinity and saltwater with a gradually increasing salinity downwards. The electromagnetic log itself showed formation conductivity levels of typically $<50 \mathrm{mS} / \mathrm{m}$ above the freshwater/saltwater interface and $>100 \mathrm{mS} / \mathrm{m}$ below. The interface was, however, more distinctly defined in the calculated logs, typically within $1 \mathrm{~m}$, compared to 1-2 $\mathrm{m}$ for the electromagnetic log alone. 
TDEM soundings were used to fill out the areas between the observation wells. The TDEM method was chosen due to its profound ability of detecting conductive soil layers, e.g. Fitterman \& Stewart (1986), Stewart \& Gay (1986).
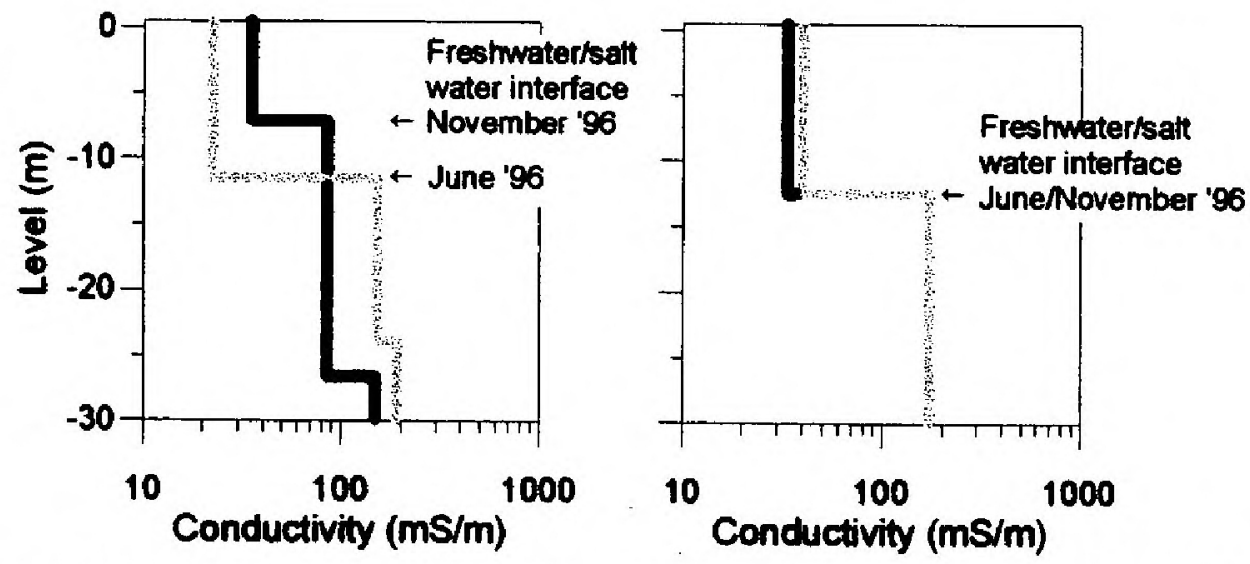

Fig. 2. Interpretation of TDEM soundings at two localities carried out at the upstart of the ground water table lowering (June '96) and at the end of the lowering (November '96). At the locality shown in the left drawing a rise of the freshwater/saltwater interface of $c .4 \mathrm{~m}$ is observed, whereas no change is observed at the other locality.

The soundings were carried out using $20 * 20 \mathrm{~m}$ and $40 * 40 \mathrm{~m}$ transmitter loops, depending on the space available. The soundings showed that the soil layers exhibit an upper succession with formation conductivity levels generally $<50 \mathrm{mS} / \mathrm{m}$ and a lower succession with conductivities generally $>80-100 \mathrm{mS} / \mathrm{m}$ (Fig. 2). These values corresponded to the values observed in the electromagnetic logs and they were interpreted as representing the freshwater and saltwater zones, respectively. The freshwater/saltwater interface was well defined within $1-2 \mathrm{~m}$.

\section{RESULTS}

The two geophysical methods, borehole logging and TDEM, supplement each other very well and provide a coherent picture of the saltwater situation in the area of interest. Accordingly, it was possible to construct a contour map of the freshwater/saltwater interface position before the actual ground water lowering and after more than 4 months of lowering (Fig. 3).

The results show that a very limited change in the position of the freshwater/saltwater interface occurred. At the majority of the wells and sounding localities no or only 1-2 m rise of the interface occurred during the excess ground water lowering. The largest change, observed at a single locality, was a rise of $4 \mathrm{~m}$.

The interface dipped approximately $3 \%$ towards ENE south of the alignment whereas immediately around the Øresund alignment a gradient of only c. 1.5\% was observed (Fig. 3). This picture occurred both prior to and during the excess ground water lowering. Accordingly, the general lowering of the ground water table during the land works for the Øresund alignment, prior to the present excess lowering, probably had a profound influence on the saltwater situation, whereas the present excess lowering only had a limited - although measurable - effect.

\section{CONCLUSIONS}

The investigations show that it is extremely important to analyze the actual conditions and choose the proper geophysical tools considering these conditions. Specifically in the present 
case the use of fluid conductivity logs should be avoided due to a mismatch in the salinity profile of the well water compared to the formation water.

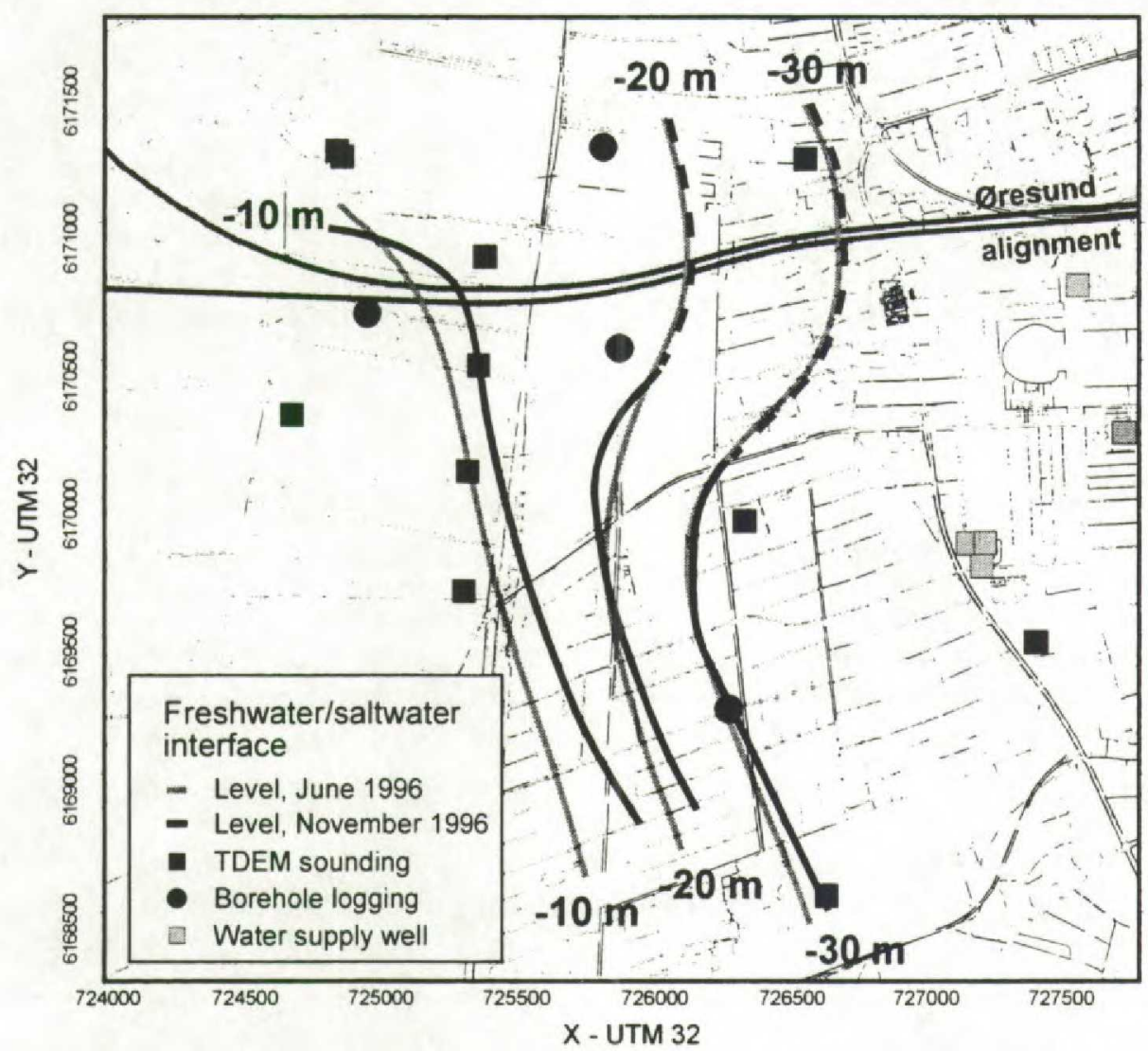

Fig. 3. Contour map showing the level of freshwater/saltwater interface at the upstart of the ground water table lowering (June '96) and at the end of the lowering (November '96). The abstraction of water for the excess lowering occurred at the Øresund alignment where the two $-10 \mathrm{~m}$ contours cross the alignment.

The example illustrates the advantages of geophysical well logging with electromagnetic and porosity tools. Furthermore the advantages of complementing the observation wells with TDEM soundings is demonstrated. The use of the cheaper surface geophysical methods minimises the expenses for monitoring the ground water conditions.

\section{REFERENCES}

Fitterman, D. V. and Stewart, M. T. (1986): Transient electromagnetic sounding for groundwater. Geophysics, 51, 995-1005.

Schlumberger (1989): Log interpretation, principles/applications. Schlumberger Educational Services, Houston, 2-1 - 2-9.

Stewart, M. and Gay, M. C. (1986): Evaluation of transient electromagnetic soundings for deep detection of conductive fluids. 